labour ${ }^{21}$ but is unlikely to cause a rapid increase in the third stage because the increase was delayed in some patients until after the umbilical cord had been clamped and cut. If the increase in oxytocin is maternal in origin it may be due to increased release from the posterior pituitary or a sudden reduction in metabolism. Suddenly reduced metabolism is perhaps unlikely because the placenta (the main source of oxytocinase) was removed after the increase in oxytocin concentration. The posterior pituitary is thus the likely source of the endogenous oxytocin; it is tempting to suggest that vaginal distension during delivery could cause the release of oxytocin as a result of the Ferguson reflex."

In conclusion, in $40 \%$ of the women who did not receive oxytocin treatment plasma concentrations of endogenous oxytocin increased. The increase was similar to that that always occurs after intramuscular administration of synthetic oxytocin. As yet we cannot predict in which women the increase will occur; therefore, assuming that the increase is important in the natural third stage of delivery we advise that oxytocin should be given routinely.

We thank the consultants of the Princess Mary Maternity Hospital for allowing us to study their patients, the women themselves, and the department of medical statistics, University of Newcastle upon Tyne. We are grateful for financial support from the research committee, Newcastle Health Authority (reference 86/56).

1 Turnbull AC, Tindall VR, Robson G, Dawson IMP, Cloake EP, Ashley JSA. Report on confidential enquiries into maternal deaths, 1979-1981. London HMSO, 1986.

2 Anonymous. Should third stage of labour be managed actively? [Editorial.] Lancet 1986;ii:22-4.
3 Inch S. Birthrights. A purent's guide to modern childbirth. London: Hutchinson, 1982.

Inch S. Management of the third stage of labour-another cascade of intervention. Midwifer 1985;1:114-22.

5 Gibbens GLD, Boyd NRH, Chard T, Croker S, Baumber S. Circulating levels of oxytocin following IV and IM administration of Syntometrine. Fournal of Obstetrics and Gynuecolog, of the British Commonzealth 1972:79.644-6.

6 Elbourne D, Prendiville $\mathrm{W}$, Chalmers I. Choice of oxytocin preparation for routine use in the management of the third stage of labour: an overview of routine use in the management of the third stage of labour: an overview
the evidence from controlled trials. Br O Obstet Gynaecol 1988:95:17-30.

Chard T, Boyd NRH, Forsling ML, McNeilly AS, Landon J. The development of a radioimmunoassay for oxytocin: the extraction of oxytocin from plasma and its measurement during parturition in human and goat blood. F Endocrinol 1970;48:223-4.

8 Chard T. The radioimmunoassay of oxytocin and vasopressin. $\mathcal{F}$ Endocrinol 1973;58:143-60

9 Kumaresan P, Anandarangam PB, Diazon W, Vasika A. Plasma oxytocin levels during pregnancy and labor as determined by radioimmunoassav. Am F Obstet (iynecol 1974;119:215-23.

10 Summerlee AJS. Extracellular recordings from oxvtocin neurones during the expulsive phase of birth in unanaesthetized rats. F Physiol (Lond) 1981; $321: 1.9$.

11 Fuchs A-R. Oxytocin in animal parturition. In: Amico JA, Robinson AG, eds. Oxytocin: climical and laboraton' studies. Amsterdam: Elsevier North Holland, 1985:207-35.

12 Amico JA, Seitchik KJ, Robinson AG. Studies of oxvtocin in plasma of women during hypocontractile labor. I Clin Endocrinol Metah 1984;58:274-9.

13 Thornton S, Davison JM, Baylis PH. A novel strategy for inhibition of oxytocinase activity during frequent blood sampling [Abstract]. Clin Sci 1987;73 (suppl 17):13P

14 Brandt ML. The mechanism and management of the third stage of labor. $A m f$ Obstet (jynecol 1933;23:662-7.

15 Andrews CJ. Third stage of labour with evaluation of Brandt method of expression of placenta. Southern Medicine and Surgery 1940;102:605-8.

16 Burd JM. Davison JM, Weightman DR, Bavlis PH. Evaluation of enzyme inhibitors of pregnancy associated oxytocinase: application to the measurement of plasma immunoreactive oxytocin during human labour. Acta Endocrinol (Copenh) 1987;114:458-64.

17 Beardwell CG. Radioimmunoassay of arginine vasopressin in human plasma. Journal of Climical Endocrinology and Metabolism 1971;33:254-60.

8 Rooke P. Baylis PH. A new and sensitive radioimmunoassav for plasma . Baylis PH. A new and sensituve radioim

arg $W$. Burd JM, Weightman DR, Baylis PH. Solid phase radioinmunoassay for the direct measurement of human plasma oxytocin. 7 Immunoassay 1985;6.

20 Chard T, Hudson CN, Edwards CRW, Boyd NRH. Release of oxytocin and vasopressin by the human fetus during labour. Nature 1971;234:352-3.

21 Ferguson JKW. A study of the intact uterus at term. Surg Gynecol (Obstet 1941;73:359-66.

Accepled 12 April 1988
Department of Medicine, University Hospital, Queen's Medical Centre, Nottingham NG7 2UH A J Cowley, MRCP, lecturer R D Wynne, MB, clinical assistant

K Stainer, BSC, research assistant

L Fullwood, technician

J M Rowley, MRCP, lecturer

J R Hampton, FRCP, professor

of cardiology

Correspondence to: $\mathrm{Dr}$ Cowley.

\section{Flosequinan in heart failure: acute haemodynamic and longer term symptomatic effects}

\author{
A J Cowley, R D Wynne, K Stainer, L Fullwood, J M Rowley, J R Hampton
}

present. Not all vasodilators are effective, however, and the reason is not clear.

In acute heart failure vasodilators may increase cardiac output and reduce high pulmonary capillary wedge pressures, but in chronic heart failure these changes do not correlate with patients' symptoms. ${ }^{1}$ In chronic heart failure exercise tolerance is related to limb and therefore skeletal muscle blood flow and vasodilators may be more important in improving skeletal muscle blood flow than in changing central haemodynamics. ${ }^{2}$

In chronic heart failure the renin-angiotensin and sympathetic nervous systems are often activated and both may further be activated by diuretics; this may limit the efficacy of these agents. ${ }^{3}$ The angiotensin converting enzyme inhibitors partially reverse these neurohumoral changes, which may explain their long term symptomatic benefit. ${ }^{45}$ Conversely, other vasodilators that stimulate the renin-angiotensin and sympathetic nervous systems may not produce long term benefit. ${ }^{6}$

Though angiotensin converting enzyme inhibitors are used routinely for treating severe heart failure, they are not ideal; some patients fail to respond and others develop undesirable side effects. New vasodilators are clearly needed but there is no simple way of evaluating them. Apart from vasodilator activity they must be 
shown to improve symptoms when given long term and they should also be shown not to potentiate the neurohumoral responses to heart failure.

We describe two studies evaluating the acute haemodynamic and longer term symptomatic effects of flosequinan, a new, direct acting venous and arteriolar vasodilator, ${ }^{7}$ in patients with heart failure.

\section{Patients and methods ACUTE HAEMODYNAMIC EFFECTS}

Ten patients with chronic heart failure due to ischaemic heart disease entered the study. Two were withdrawn; one developed ventricular tachycardia 10 hours after taking the drug and in the other patient the drug could not be detected in plasma samples. The eight who completed the study were aged 46-70, and two were women. All the patients were taking 160-200 mg frusemide daily. The patients were admitted to hospital because of uncontrolled heart failure and were considered to need vasodilators. They were in hospital for at least 24 hours before the study. On the study day a thermodilution catheter was inserted into the pulmonary artery at least two hours before the baseline measurements. Cardiac output was measured in triplicate by an Edwards cardiac output computer, model 9520A. Intracardiac pressures were measured with reference to the midaxilla, systemic arterial blood pressure was measured by a sphygmomanometer, and the electrocardiogram was monitored continuously.

After baseline measurements $100 \mathrm{mg}$ flosequinan was given by mouth and cardiac output, intracardiac pressures, systemic arterial blood pressure, and heart rate measured at 30 minute intervals for two hours, then hourly up to eight hours, and again after 24 hours.

\section{LONGER TERM SYMPTOMATIC EFFECTS}

\section{Exercise tolerance}

A different group of 16 patients with chronic heart failure who continued to have symptoms despite $80-500 \mathrm{mg}$ frusemide daily entered the study. Five failed to complete. One patient died suddenly during the incremental dose period, another had a gastrointestinal bleed secondary to a duodenal ulcer, and a third patient deteriorated during the incremental dose period. This patient also failed to respond to angiotensin converting enzyme inhibitors and was later given a heart transplant. The fourth patient deteriorated during the double blind placebo period and could not exercise on a treadmill, and the last patient was withdrawn because of a dispensing error. Of the patients who completed the study, 10 had ischaemic heart disease and one dilated cardiomyopathy. Their ages ranged between 46 and 70. None was taking a vasodilator and in all cases treatment had been stable for six weeks before the study. The dose of all drugs except flosequinan was kept constant throughout.

Patients were evaluated at weekly intervals. At each visit they performed a symptom limited exercise test on a treadmill. The speed and slope of the treadmill were increased after three minutes at each of the following stages-stage 1: $2 \cdot 7 \mathrm{kph}, 0$ degree; stage $2: 2 \cdot 7 \mathrm{kph}$, $1 \cdot 3$ degrees; stage $3: 2.7 \mathrm{kph}, 2.6$ degrees; stage 4 : $2 \cdot 7 \mathrm{kph}, 4 \cdot 3$ degrees; stage $5: 4 \cdot 0 \mathrm{kph}, 5 \cdot 4$ degrees; stage 6: $5.5 \mathrm{kph}, 6.3$ degrees; stage $7: 6.8 \mathrm{kph}$, $7 \cdot 2$ degrees. At the end of each completed stage of exercise perceived exertion was measured with a Borg score. ${ }^{8}$

Minute ventilation, oxygen consumption, and carbon dioxide production were measured at minute intervals during the exercise test with an on line gas analyser (P K Morgan). Blood was sampled from an antecubital vein with the patients supine, erect, and at symptom limited maximum for plasma renin activity and noradrenaline concentrations.

\section{Limb blood flow}

The effect of flosequinan on limb blood flow was measured before and after a second exercise test. Sixty minutes after the symptom limited exercise test, by which time limb blood flow had returned to preexercise levels, the patients performed a submaximal test. They were asked to exercise to a workload which required an oxygen consumption of $12 \mathrm{ml} / \mathrm{kg} / \mathrm{min}$. If they failed to reach this workload the submaximal test was terminated at the last completed stage before the one in which the patient became limited by symptoms. The workload of this test was kept constant for each patient throughout. Forearm and calf blood flow were measured by venous occlusion plethysmography with mercury in Silastic strain gauges at rest before the test and at minute intervals from three to 13 minutes after the end of the test. ${ }^{2}$

\section{Plasma renin activity and catecholamines}

Plasma renin activity was measured by radioimmunoassay (Rianen angiotensin I (iodine-125) radioimmunoassay kit) and plasma catecholamine concentrations by high performance liquid chromatography. ${ }^{9}$

\section{Study design and drug administration}

The study had a randomised, double blind crossover design which after a dose titration phase compared placebo with active treatment. Each patient was treated with placebo at the start of the study until two consecutive symptom limited exercise times did not increase by more than 5\%. Over the next five weeks the patients were given single blind weekly incremental doses of flosequinan of $30 \mathrm{mg}, 50 \mathrm{mg}, 75 \mathrm{mg}, 100 \mathrm{mg}$, and $125 \mathrm{mg}$ once daily. The optimum dose of flosequinan was chosen and the patients received this or placebo in a double blind manner for the next four weeks, according to a randomisation schedule, and were then crossed over to the other treatment for a further four weeks. If they deteriorated before the end of the first four weeks they were immediately given the other treatment, and if they deteriorated before the end of the second four weeks the study was terminated.

\section{STATISTICAL ANALYSIS}

For the first study the mean changes in central haemodynamics between baseline and each posttreatment measurement time were analysed by a paired $t$ test with significance determined by reference to Dunnett's multiple comparison tables. Dunnett's tables were used to preserve an overall $5 \%$ significance level for multiple testing.

Analysis of variance was carried out on the changes in exercise time, Borg scores, minute ventilation, and catecholamine concentrations and plasma renin activity between the double blind periods of the second study. Repeated measures analysis of variance was used to analyse the changes in limb blood flow after exercise. Tests were performed for the effects of treatment, period, and carryover. The Shapiro-Wilk test for normality and examination of the residuals were performed for each variable to check the test assumptions. The catecholamine data exhibited moderate deviations from normality, but these were judged insufficient to invalidate the tests.

\section{ETHICS}

The studies were approved by the local ethical committee. They were conducted under the clinical 
trial exemption scheme of the Department of Health and Social Security, and flosequinan had not been evaluated by the Committee on the Safety of Medicines.

\section{Results}

ACUTE HAEMODYNAMIC EFFECTS

The mean (SEM) pretreatment cardiac index was $1.8(0 \cdot 1) \mathrm{l} / \mathrm{min} / \mathrm{m}^{2}$. It increased significantly at three hours to a mean of $2 \cdot 1(0.1) \mathrm{l} / \mathrm{min} / \mathrm{m}^{2}(\mathrm{p}<0.05)$ and at 24 hours to $2 \cdot 2(0 \cdot 2) \mathrm{l} / \mathrm{min} / \mathrm{m}^{2}(\mathrm{p}=0 \cdot 04)$. Table I shows the mean increase in cardiac index over the 24 hour study period and table II the individual maximum values of cardiac index obtained and the times at which they occurred. All the patients showed an increase in cardiac index.

The mean (SEM) pulmonary capillary wedge pressure before flosequinan was $30.9(3 \cdot 2) \mathrm{mm} \mathrm{Hg}$. It fell to a nadir of $19 \cdot 4(2 \cdot 1) \mathrm{mm} \mathrm{Hg}$ after two hours and was $20.3(2.4) \mathrm{mm} \mathrm{Hg}$ at 24 hours $(\mathrm{p}<0.01)$. Table III shows the mean decrease in pulmonary capillary wedge pressure over the study period. Table II shows the individual minimum values of pulmonary capillary wedge pressure recorded and the times at which these occurred. All patients showed a decrease in pulmonary capillary wedge pressure.

TABLE I-Mean changes from baseline in cardiac index

\begin{tabular}{|c|c|c|c|c|}
\hline $\begin{array}{l}\text { Time } \\
\text { (hours) }\end{array}$ & $\underset{\left(1 / \mathrm{min} / \mathrm{m}^{2}\right)}{\text { Mean increase }}$ & $t$ & df & Significance \\
\hline 0.5 & $0.15(0.13)(\mathrm{n}=8)$ & $1 \cdot 17$ & 7 & $p>0 \cdot 10$ \\
\hline $1 \cdot 0$ & $0.23(0.07)(\mathrm{n}=8)$ & 3.13 & 7 & $0.05<\mathrm{p}<0.10$ \\
\hline 1.5 & $0.25(0.14)(\mathrm{n}=8)$ & 1.87 & 7 & $p>0 \cdot 10$ \\
\hline $2 \cdot 0$ & $0.28(0.11)(\mathrm{n}=8)$ & 2.53 & 7 & $p>0.10$ \\
\hline 3.0 & $0.35(0.08)(\mathrm{n}=8)$ & $4 \cdot 32$ & 7 & $p<0.05$ \\
\hline $4 \cdot 0$ & $0.38(0.11)(\mathrm{n}=8)$ & $3 \cdot 37$ & 7 & $0.05<\mathrm{p}<0.10$ \\
\hline $5 \cdot 0$ & $0.29(0.09)(n=6)$ & $3 \cdot 16$ & 5 & $p>0 \cdot 10$ \\
\hline $6 \cdot 0$ & $0.15(0.10)(\mathrm{n}=8)$ & 1.54 & 7 & $p>0.10$ \\
\hline $7 \cdot 0$ & $0.20(0.12)(n=8)$ & $1 \cdot 71$ & 7 & $\mathrm{p}>0.10$ \\
\hline $8 \cdot 0$ & $0.23(0.11)(\mathrm{n}=8)$ & $2 \cdot 10$ & 7 & $p>0 \cdot 10$ \\
\hline $24 \cdot 0$ & $0.45(0.22)(\mathrm{n}=8)$ & - & - & $0 \cdot 04^{\star}$ \\
\hline
\end{tabular}

$\star_{t}$ Test inappropriate owing to non-normality; value quoted from Wilcoxon signed rank test.

TABLE II-Time and maximum value of cardiac index and time and minimum value of pulmonary capillary wedge pressure

\begin{tabular}{|c|c|c|c|c|c|c|}
\hline \multirow[b]{2}{*}{ Case No } & \multicolumn{3}{|c|}{ Cardiac index $\left(1 / \mathrm{min} / \mathrm{m}^{2}\right)$} & \multicolumn{3}{|c|}{ Pulmonary capillary wedge pressure $(\mathrm{mm} \mathrm{Hg}$} \\
\hline & $\begin{array}{l}\text { Baseline } \\
\text { value }\end{array}$ & $\begin{array}{c}\text { Maximum } \\
\text { value }\end{array}$ & $\begin{array}{l}\text { Time of } \\
\text { maximum value } \\
\text { (hours) }\end{array}$ & $\begin{array}{l}\text { Baseline } \\
\text { value }\end{array}$ & $\begin{array}{l}\text { Minimum } \\
\text { value }\end{array}$ & $\begin{array}{c}\text { Time of } \\
\text { minimum value } \\
\text { (hours) }\end{array}$ \\
\hline 1 & $2 \cdot 36$ & $2 \cdot 43$ & $3 \cdot 0$ & 24 & 10 & $3 \cdot 0$ \\
\hline 2 & 1.37 & $2 \cdot 09$ & $2 \cdot 0$ & 49 & 24 & $2 \cdot 0$ \\
\hline 3 & 1.59 & $2 \cdot 18$ & 0.5 & 30 & 20 & $6 \cdot 0$ \\
\hline 4 & 1.85 & 2.57 & $4 \cdot 0$ & 36 & 26 & 1.5 \\
\hline 5 & 1.76 & $2 \cdot 26$ & $7 \cdot 0$ & 23 & 14 & $2 \cdot 0$ \\
\hline 6 & 1.92 & 3.76 & $24 \cdot 0$ & 25 & 12 & 1.0 \\
\hline 7 & 1.49 & 2.05 & 6.0 & 24 & 12 & 1.5 \\
\hline 8 & 1.87 & $2 \cdot 16$ & $4 \cdot 0$ & 36 & 24 & 3.0 \\
\hline Mean (SEM) & $1.78(0.11)$ & $2.44(0.20)$ & $\star$ & $30 \cdot 9(3 \cdot 2)$ & $17 \cdot 8(2 \cdot 3)$ & $2 \cdot 5(0 \cdot 6)$ \\
\hline
\end{tabular}

^Not calculated because of outlying value at 24 hours.

TABLE III-Mean changes from baseline in pulmonary capillary wedge pressure

\begin{tabular}{|c|c|c|c|c|}
\hline Time (hours) & $\begin{array}{c}\text { Mean decrease (SEM) } \\
(\mathrm{mm} \mathrm{Hg})\end{array}$ & $t$ & df & Significance \\
\hline 0.5 & $5 \cdot 6(1 \cdot 3)(\mathrm{n}=8)$ & $4 \cdot 17$ & 7 & $\mathrm{p}<0.05$ \\
\hline $1 \cdot 0$ & $8 \cdot 7(1 \cdot 1)(\mathrm{n}=8)$ & $7 \cdot 64$ & 7 & $\mathrm{p}<0.001$ \\
\hline 1.5 & $9 \cdot 8(1 \cdot 3)(n=8)$ & $7 \cdot 62$ & 7 & $\mathrm{p}<0.001$ \\
\hline $2 \cdot 0$ & $10 \cdot 4(2 \cdot 2)(n=8)$ & $4 \cdot 80$ & 7 & $\mathrm{p}<0.05$ \\
\hline $3 \cdot 0$ & $9 \cdot 4(1.9)(n=8)$ & $4 \cdot 88$ & 7 & $p<0.05$ \\
\hline $4 \cdot 0$ & $10 \cdot 2(1 \cdot 7)(n=8)$ & 6.07 & 7 & $\mathrm{p}<0.01$ \\
\hline $5 \cdot 0$ & $7 \cdot 8(2 \cdot 7)(n=6)$ & $2 \cdot 90$ & 5 & $p>0 \cdot 10$ \\
\hline $6 \cdot 0$ & $9 \cdot 9(1.8)(\mathrm{n}=8)$ & $5 \cdot 54$ & 7 & $\mathrm{p}<0.01$ \\
\hline $7 \cdot 0$ & $8.9(1.7)(n=8)$ & $5 \cdot 17$ & 7 & $p<0.01$ \\
\hline $8 \cdot 0$ & $6 \cdot 6(2 \cdot 1)(n=8)$ & $3 \cdot 16$ & 7 & $0.05<\mathrm{p}<0.10$ \\
\hline $24 \cdot 0$ & $8.9(1.8)(n=8)$ & $5 \cdot 05$ & 7 & $\mathrm{p}<0.01$ \\
\hline
\end{tabular}

There were no significant changes in systemic arterial pressure or heart rate during the study.

\section{LONGER TERM SYMPTOMATIC EFFECTS}

\section{Exercise tolerance}

During the single blind dose ranging phase of the study all 11 patients were found to improve most with $125 \mathrm{mg}$ daily, and this dose was therefore chosen for all patients during the double blind phase.

Figure 1 shows the changes in symptom limited exercise time on the treadmill during the double blind crossover phase of the study and also the exercise time at the end of the placebo run in period. There was no difference between the mean (SEM) exercise time at the end of the placebo run in period $(9 \cdot 2(1 \cdot 6)$ minutes and that at the end of the double blind placebo period ( $9.9(1.6)$ minutes), indicating that the patients were stable. There was a significant increase from the double blind placebo exercise time of $9 \cdot 9(1 \cdot 6)$ minutes to $12 \cdot 7$ $(1 \cdot 3)$ minutes after four weeks of active treatment (treatment effect: $\mathrm{F}=31 \cdot 8, \quad \mathrm{df}=1,5 \cdot 9$ (assuming unequal variances) $p=0.001)$. There was no evidence of tachyphylaxis to the drug over the treatment period.

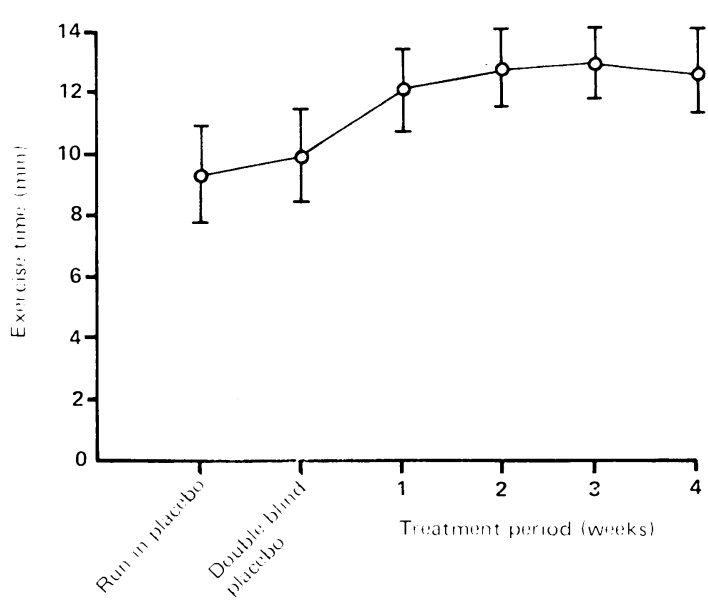

FIG 1-Mean values of symptomatic limited exercise tolerance. Bars are SEM. (Double blind placebo period versus active treatment, $p=0.001)$

In addition to increasing exercise tolerance, flosequinan reduced the patients' perceived exertion during submaximal exercise (table IV). Mean Borg score fell from 10.6 (SEM 0.8) during the double blind placebo period to $9.5(0.7)$ after four weeks of active treatment in the 11 patients who completed stage 1 of the treadmill exercise protocol (treatment effect: $\mathrm{F}=2 \cdot 22, \mathrm{df}=1,9 ; \mathrm{p}=0 \cdot 17)$. In the nine patients who completed stage 2 it fell from a placebo value of $12 \cdot 4$ $(1 \cdot 2)$ to $11 \cdot 2(1 \cdot 1)$ after four weeks of active treatment (treatment effect: $\mathrm{F}=5 \cdot 85, \mathrm{df}=1,4 \cdot 6$ (assuming unequal variances); $\mathrm{p}=0 \cdot 06$ ).

Resting values of minute ventilation were reduced from a mean (SEM) of $13.7(1 \cdot 2) 1 / \mathrm{min}$ during the double blind placebo period to $11 \cdot 3(0.6) 1 / \mathrm{min}$ after four weeks of flosequinan (treatment effect: $F=4.97$, $\mathrm{df}=1,9 ; \mathrm{p}=0.052)$. Values at the end of stage 1 of the exercise protocol were $22 \cdot 3(1.5) \mathrm{l} / \mathrm{min}$ with placebo and $19.0(0.9) 1 / \mathrm{min}$ after four weeks of flosequinan (treatment effect: $\mathrm{F}=7 \cdot 39, \mathrm{df}=1,9 ; \mathrm{p}=0.02$ ) and the end of stage $2,29 \cdot 1(2.9) \mathrm{l} / \mathrm{min}$ with placebo and 23.6 (1.5) $1 / \mathrm{min}$ with flosequinan (treatment effect: $\mathrm{F}=5 \cdot 33, \mathrm{df}=1,7 ; \mathrm{p}=0 \cdot 05$ ) table IV)

\section{Effects on limb blood flow}

Figure 2 shows the changes in calf blood flow before and after exercise during the double blind part of the study. Normal resting calf blood flow is approximately $3.0 \mathrm{ml} / \mathrm{dl} / \mathrm{min}$, and in response to the same workload a 
normal person would increase calf blood flow to greater than $5.0 \mathrm{ml} / \mathrm{dl} / \mathrm{min}$ three minutes after the end of exercise. ${ }^{2}$ Thus the patients had a reduced blood flow at rest and the response to exercise was also attenuated.

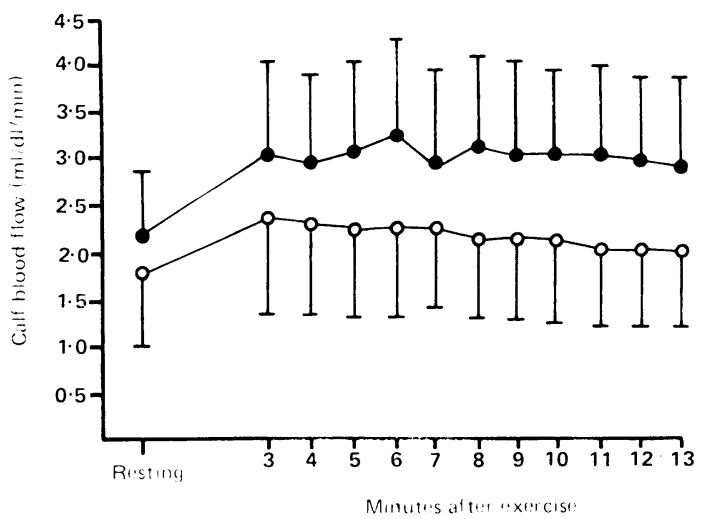

FIG 2-Mean values of calf blood flow at rest and from three to 13 minutes after exercise during placebo $\left(\mathrm{O}^{-} \bigcirc\right)$ and after four weeks of flosequinan (-) Bars are SEM. $(p<0.001)$

Flosequinan increased calf blood flow at rest and after exercise (treatment effect: $F=74 \cdot 48, d f=1,9$; $\mathrm{p}<0.001$ ).

The normal response to upright exercise is to redirect blood from the non-exercising forearm to the exercising calf and thereby cause a fall in forearm blood flow. With placebo forearm blood flow fell from a mean of $1.9($ SEM 0.2$) \mathrm{ml} / \mathrm{dl} / \mathrm{min}$ at rest to 1.6 $(0.3) \mathrm{ml} / \mathrm{dl} / \mathrm{min}$ three minutes after exercise and remained at this level up to 13 minutes after exercise. Flosequinan increased resting forearm blood flow to $2.6(0 \cdot 2) \mathrm{ml} / \mathrm{dl} / \mathrm{min}$, and three minutes after exercise the value was $2 \cdot 2(0 \cdot 3) \mathrm{ml} / \mathrm{dl} / \mathrm{min}$; and it also remained at this level up to 13 minutes after exercise (treatment effect: $F=6 \cdot 25, \mathrm{df}=1,9 ; \mathrm{p}=0 \cdot 03$ ) (table IV).

\section{Plasma renin activity and catecholamines}

Table IV also gives the supine plasma renin activity and plasma noradrenaline concentrations at rest and during exercise during the double blind part of the study. There were no significant differences between any of the measurements, but the mean supine plasma renin activity tended to fall with active treatment and mean plasma noradrenaline concentrations were lower both supine and erect with active treatment. Plasma noradrenaline concentrations at symptom limited maximum exercise were similar despite the mean exercise tolerance of the patients being considerably greater with flosequinan.

TABLE IV-Summary of mean, differences of mean, and $95 \%$ confidence intervals for results obtained at end of double blind periods of flosequinan and placebo

\begin{tabular}{|c|c|c|c|c|}
\hline & $\begin{array}{c}\text { Flosequinan } \\
(\text { mean }(\text { SEM }))\end{array}$ & $\begin{array}{c}\text { Placebo } \\
(\text { mean }(\text { SEM }))\end{array}$ & $\begin{array}{l}\text { Difference } \\
\text { (SEM) }\end{array}$ & $\begin{array}{l}95 \% \text { Confidence } \\
\text { interval }\end{array}$ \\
\hline Exercise time (min) & $12 \cdot 7(1 \cdot 3)$ & $9 \cdot 9(1 \cdot 6)$ & $2 \cdot 8(0.5)$ & 1.6 to 4.0 \\
\hline Borg score: & & & & \\
\hline $\begin{array}{l}\text { Stage } 1 \\
\text { Stage }\end{array}$ & $9 \cdot 5(0 \cdot 7)$ & $10 \cdot 6(0.8)$ & $-1 \cdot 1(0 \cdot 7)$ & $\begin{array}{l}-2.7 \text { to } 0.5 \\
-2.5 \text { to } 0.1\end{array}$ \\
\hline $\begin{array}{l}\text { Stage } 2 \\
\text { Minute ventilation (1): }\end{array}$ & $11 \cdot 2(1 \cdot 1)$ & $12 \cdot 4(1 \cdot 2)$ & $-1 \cdot 2(0 \cdot 5)$ & $-2 \cdot 5$ to $0 \cdot 1$ \\
\hline $\begin{array}{l}\text { Resting } \\
\text { Stage } 1 \\
\text { Stage } 2\end{array}$ & $\begin{array}{l}11.3(0.6) \\
19.0(0.9) \\
23.6(1.5)\end{array}$ & $\begin{array}{l}13 \cdot 7(1 \cdot 2) \\
22 \cdot 3(1 \cdot 5) \\
29 \cdot 1(2 \cdot 9)\end{array}$ & $\begin{array}{l}-2 \cdot 4(1 \cdot 1) \\
-3 \cdot 4(1 \cdot 3) \\
-5 \cdot 8(2 \cdot 5)\end{array}$ & $\begin{array}{l}-4.9 \text { to }-0.1 \\
-6.3 \text { to }-0.5 \\
-11.7 \text { to } 0.1\end{array}$ \\
\hline Calf blood flow $(\mathrm{ml} / \mathrm{dl} / \mathrm{min})$ : & & & & \\
\hline $\begin{array}{l}\text { Resting } \\
\text { Overall }\end{array}$ & $\begin{array}{l}2 \cdot 2(0 \cdot 2) \\
3 \cdot 0(0 \cdot 3)\end{array}$ & $\begin{array}{l}1 \cdot 8(0 \cdot 2) \\
2 \cdot 3(0 \cdot 3)\end{array}$ & $\begin{array}{l}0.4(0 \cdot 1) \\
0.9(0 \cdot 1)\end{array}$ & $\begin{array}{l}0.2 \text { to } 0.6 \\
1 \cdot 1 \text { to } 0.7\end{array}$ \\
\hline Forearm blood flow $(\mathrm{ml} / \mathrm{dl} / \mathrm{min})$ : & & & & \\
\hline $\begin{array}{l}\text { Resting } \\
\text { Overall }\end{array}$ & $\begin{array}{l}2 \cdot 6(0 \cdot 2) \\
2 \cdot 1(0 \cdot 2)\end{array}$ & $\begin{array}{l}1.9(0.2) \\
1.6(0.2)\end{array}$ & $\begin{array}{l}0.7(0.1) \\
0.5(0.2)\end{array}$ & $\begin{array}{l}0.6 \text { to } 1.0 \\
1.0 \text { to } 0.5\end{array}$ \\
\hline Supine plasma renin activity $(\mu \mathrm{g} / / \mathrm{h})$ & $10 \cdot 4(2 \cdot 0)$ & $13 \cdot 0(3 \cdot 3)$ & $-1 \cdot 8(6 \cdot 4)$ & $-17 \cdot 5$ to 13.9 \\
\hline Noradrenaline $(\mathrm{nmol} / \mathrm{l})$ : & & & & \\
\hline $\begin{array}{l}\text { Supine } \\
\text { Erect } \\
\text { Peak exercise }\end{array}$ & $\begin{array}{r}4.14(0.52) \\
5.41(0.55) \\
11.56(1.42)\end{array}$ & $\begin{array}{r}5.78(1.53) \\
6.22(1.35) \\
10.86(1.64)\end{array}$ & $\begin{array}{r}-1.59(1.11) \\
-0.80(1.09) \\
0.79(1.36)\end{array}$ & $\begin{array}{r}-1.85 \text { to } 5.23 \\
-4.26 \text { to } 2.65 \\
2.54 \text { to } 4.11\end{array}$ \\
\hline
\end{tabular}

CARRYOVER EFFECTS AND SIDE EFFECTS

The period and carryover effects were not statistically significant in any of the analyses.

No patient developed any drug related biochemical or haematological abnormality. In the exercise study two patients complained of transient headache and two had a taste disturbance, probably due to the excretion of the drug in saliva.

\section{Discussion}

The first of these studies shows that flosequinan had favourable central haemodynamic effects in patients with severe heart failure. These effects lasted up to 24 hours after a single oral dose. This is because the drug has an active metabolite with a half life exceeding 30 hours $^{10}$ and is therefore suitable for once daily use. In the second study the drug also improved the symptom limited exercise tolerance of patients with severe heart failure.

It has been suggested that the efficacy of direct acting vasodilators may be limited because they further stimulate the renin-angiotensin and sympathetic nervous systems and therefore lead to tolerance. ${ }^{11}$ The changes in symptom limited exercise time in our patients suggest a lack of development of tolerance to flosequinan, the improvement in exercise tolerance being maintained over the four weeks of treatment. Furthermore, both plasma renin activity and plasma noradrenaline concentrations tended to fall during the study, indicating a lack of stimulation of these systems.

Though we cannot make direct comparisons with other studies, the improvement in exercise time of three minutes was similar to that we have found with captopril using the same exercise protocol. ${ }^{12}$ It was also associated with a reduction in the perceived exertion of the patients during submaximal exercise and therefore probably indicates worthwhile symptomatic improvement.

We have previously shown that the ventilatory effort of patients with heart failure as measured by minute ventilation is excessive both at rest and during exercise. ${ }^{2}$ Flosequinan reduced minute ventilation at rest and during submaximal exercise, which may have contributed to the reduced perceived exertion of the patients as shown by the change in Borg scores during exercise.

The cause of the increased ventilatory effort of patients with heart failure is likely to be multifactorial. In part it may be due to high left ventricular filling pressure which leads to increased lung stiffness and even frank pulmonary oedema. It may also in part be due to respiratory compensation for metabolic acidosis, particularly during exercise. This metabolic acidosis results from inadequate delivery of oxygen to skeletal muscle during exercise and ultimately limb blood flow. The patients in this study had a reduced calf blood flow at rest and after exercise when compared with a group of normal men who exercised to the same workload. ${ }^{2}$ The effect of flosequinan was to improve resting calf blood flow and increase blood flow after exercise. Probably, therefore, it also improved calf blood flow during exercise and therefore oxygen delivery to actively metabolising skeletal muscle. This would delay the onset of anaerobic metabolism.

Flosequinan is a newly developed mixed arteriolar and venous vasodilator. It improves the central haemodynamics and exercise tolerance of patients with heart failure. Unlike some vasodilators it does not cause reflex stimulation of the renin-angiotensin or sympathetic nervous system. These effects are similar to those of angiotensin converting enzyme inhibitors, ${ }^{4}$ though the mechanism of action of flosequinan is completely different. Angiotensin converting enzyme inhibitors should not, therefore, be thought of as 
having a unique role in the management of patients with heart failure, particularly as they are not always well tolerated. Flosequinan undoubtedly has the properties theoretically desirable in a vasodilator to be used to treat patients with heart failure, and the improvement in symptoms that we have recorded suggests that it is likely to be a useful alternative to angiotensin converting enzyme inhibitors.

We thank the Boots Company, Nottingham, for financial support.

1 Franciosa JA, Goldsmith SR, Cohn JN. Contrasting immediate and long-term effects of isosorbide dinitrate on exercise capacity in congestive heart failure. Am F Med 1980;69:559-66.

2 Cowley AJ, Stainer K, Rowley JM, Hampton JR. Abnormalities of the peripheral circulation and respiratory function in patients with severe heart peripheral circulation and respira
failure. Br Heart f 1986;55:75-80.

3 Francis GS, Siegel RM, Goldsmith SR, Olivari MT, Levine TB, Cohn JN Acute vasoconstrictor response to intravenous frusemide in patients with Acute vasoconstrictor response to intravenous frusemide in

4 Mettauer B, Rouleau J-L, Bichet D, et al. Differential long term intrarenal and neurohumoral effects of captopril and prazosin in patients with chronic the importance of initial plasma renin activity. Circulation 1986;73:492-502

5 Captopril Multicentre Research Group. A placebo controlled trial of captopri in refractory chronic congestive heart failure. $7 \mathrm{Am}$ Coll Cardiol 1983;2 in refractor.

6 Bavliss J, Norrell M, Canepa-Anson R, Reid C, Poole-Wilson PA, Sutton G. Clinical importance of the renin-angiotensin system in chronic heart failure: double blind comparison of captopril and prazosin. Br.Med f 1985;290: double

7 Cowley AJ, Wynne RD, Hampton JR. The effects of BTS 49465 on blood pressure and peripheral arteriolar and venous tone in normal volunteer Joumal of Hypertensum 1984;2:547-8.

8 Borg G. Perceived exertion as an indicator of somatic stress. Scand f Rehabil Med 1970;2:92-8.

9 Diggory GL, Buckett WR. An automated method to measure monoamines and metabolites using elevated temperature reversed phase HPLC with electrochemical detection. Application to striatal dopamine and hippocampal serotonin turnover. F Pharmacol Methods 1984:11:207-17.

10 Wynne RD, Crampton EL, Hind ID. The pharmacokinetics and haemodynamics of BTS 49465 and its major metabolite in healthy volunteers. Eur f Pharmacol 1985:28:659-64.

11 Packer M. Do vasodilators prolong life in heart failure? $N$ Engl f Med 1987;316:1471-3.

12 Cowley AJ, Ruwley JM, Stainer K, Hampton JR. Effects of captopril on abnormalitics of the peripheral circulation and respiratory function in patients with severe heart failure. Lancet 1984; ii:1120-4.

Accepted 10 May 1988

\title{
Combination treatment with cholestyramine and bezafibrate for heterozygous familial hypercholesterolaemia
}

\author{
Lloyd D Curtis, Andrew C Dickson, Kam L E Ling, John Betteridge
}

\begin{abstract}
Cholestyramine and bezafibrate were compared individually and in combination in the treatment of 18 patients with heterozygous familial hypercholesterolaemia. The study used a double blind, placebo controlled block design with a placebo run in period of two months followed by three phases of active treatment, each of two months' duration. Patients were randomly allocated to one of the six possible sequences of medication so that three patients would be treated with each sequence. Two patients withdrew from the study before completion. The median concentration of total cholesterol decreased from $9.65 \mathrm{mmol} / 1$ (interquartile range 8.62 to 8.72 ) to $7.24 \mathrm{mmol} / \mathrm{l}(6.70$ to 7.52$)$ with cholestyramine, to $8.09 \mathrm{mmol} / \mathrm{l}(7.18$ to 8.68$)$ with bezafibrate, and to $6.31 \mathrm{mmol} / 1(5.84$ to 7.27$)$ with the combination. This fall was due almost entirely to a decrease in the low density lipoprotein cholesterol concentration, and the combination was significantly more effective than either drug alone. The $98 \%$ confidence intervals for the median differences between the combination and cholestyramine and the combination and benzafibrate were 0.04 to $1.49 \mathrm{mmol} / \mathrm{l}$ and 0.51 to 2.18 $\mathrm{mmol} / \mathrm{l}$ respectively.
\end{abstract}

These results suggest that this combination is an effective and useful treatment in heterozygous familial hypercholesterolaemia.

Department of Medicine, University College and Middlesex Hospital School of Medicine, London WCIE 6JJ

Lloyd D Curtis, $\mathrm{MRCP}$ clinical lecturer Andrew C Dickson, research technician

Kam L E Ling, BSC, research biochemist

John Betteridge, MD, senior lecturer in medicine

Correspondence to: Dr Curtis.

\section{Introduction}

Familial hypercholesterolaemia is due to a single gene defect affecting the activity of receptors for low density lipoprotein. This leads to a reduction in the number of high affinity receptors for low density sequent increase in the plasma low density lipoprotein cholesterol concentration due to reduced plasma clearance. Familial hypercholesterolaemia is one of the commonest single gene disorders, having an incidence of one in 500 and affecting an estimated 100000 people in the United Kingdom. These patients have a greatly increased risk of coronary heart disease; the heterozygotes are estimated to have a $50 \%$ chance of dying lipoprotein on peripheral and hepatic cells and a con- from myocardial infarction before the age of $60,{ }^{\prime}$ and homozygotes rarely survive to the third decade. It is thus a condition in which there is a clear indication for dietary and pharmacological intervention aimed at reducing the high concentrations of low density lipoprotein. The response to diet is usually poor and treatment with a single agent is often inadequate. Combination treatment, particularly with bile acid sequestrant resins and nicotinic acid, has reduced concentrations of low density lipoprotein. ${ }^{2}$ The side effects of nicotinic acid, however, make this approach unsuitable for most patients.

We used an anion exchange resin (cholestyramine), the treatment of choice in familial hypercholesterolaemia, alone and in combination with bezafibrate, one of the newer fibrate drugs, in 18 patients with familial hypercholesterolaemia. The study compared the relative efficacy of cholestyramine and bezafibrate in lowering low density lipoprotein cholesterol concentration in patients with this condition and determined whether combination treatment could reduce low density lipoprotein to acceptable concentrations.

\section{Patients and methods}

Eighteen patients with heterozygous familial hypercholesterolaemia were recruited from the outpatient clinic. All had a total cholesterol concentration $>7 \cdot 5$ $\mathrm{mmol} / \mathrm{l}$ or a low density lipoprotein cholesterol concentration $>4.9 \mathrm{mmol} / \mathrm{l}$ (concentration before treatment or highest concentration while patient was receiving treatment), and they or a first or second degree relative had tendon xanthomas. The 10 women and eight men had a mean age of 41 (range 26 to 52 ) years.

All patients were maintained on a formal diet low in fat $(30 \%$ of total calories: $10 \%$ each of saturated, monounsaturated, and polyunsaturated fatty acids) and low in cholesterol (less than $300 \mathrm{mg} /$ day); they were provided with regular dietary counselling throughout the study. Patients with diabetes or with liver, kidney, thyroid, or parathyroid diseases were excluded, as were pregnant or lactating women. None of the patients was taking drugs known to affect lipid metabolism. 